\title{
Physician Communication in a Lung Cancer Center - Does the Message Come Across?
}

\author{
Aufklärungsgespräche in einem Lungenkrebszentrum - \\ Kommt die Botschaft an?
}

Authors

Institutions
W. Nehls ${ }^{1}$, S. Gabrijel' ${ }^{1}$, A. Kiss ${ }^{2}$, J. Kollmeier ${ }^{1}$, O. Schmalz ${ }^{3}$, H. Albrecht ${ }^{4}$, J. Behr ${ }^{5}$, T. T. Bauer ${ }^{1}$

Institutions are listed at the end of article. received 21.10.2013 accepted after revision 1.11.2013

\section{Bibliography}

Dol http://dx.doi.org/

10.1055/s-0033-1358999

Pneumologie 2013; 67: 688-693

(c) Georg Thieme Verlag KG

Stuttgart · New York

ISSN 0934-8387

\section{Corresponding author} Wiebke Nehls

Klinik für Pneumologie Lungenklinik Heckeshorn HELIOS Klinikum Emil von Behring

Walterhöferstraße 11

14165 Berlin

Germany

wiebke.nehls@helios-kliniken.de

\section{Abstract \\ $\nabla$}

Objective: Lung cancer patients require information about their diagnosis, treatment procedure and the treatment goal. We have examined recall of patients and how satisfied they were with physician communication.

Patients and Methods: 101 patients with newly diagnosed lung cancer were interviewed shortly after the disclosure of diagnosis about their diagnosis, treatment procedure and treatment goal. Disclosing physicians were asked what information they had given. Physician information and patient recall was then compared.

Results: Eighty-six percent (86 of 100 patients) knew their diagnosis, $81 \%$ recalled the treatment procedure correctly, and $42 \%$ knew if the treatment goal was curative or palliative. We found high satisfaction about communication of diagnosis and treatment procedure (83\% resp.77\%). However, satisfaction with communication of the treatment goal was 53\% (51 of 97 patients) and significantly lower than satisfaction with communication of diagnosis and of treatment procedure. Patients who were informed by male physicians were significantly more satisfied with the disclosure about the treatment goal.

Conclusions: Treatment goals are difficult to convey by untrained physicians. Further research is needed to understand how we can improve patients' understanding of and satisfaction with information about the treatment goal and prognosis and how physicians can improve their communication skills.

\section{Zusammenfassung \\ $\nabla$}

Hintergrund: Lungenkrebspatienten benötigen eine umfassende Aufklärung über ihre Diagnose, die Behandlung und das Ziel der Behandlung. Wir haben untersucht, was Lungenkrebspatienten nach dem Aufklärungsgespräch erinnerten und wie zufrieden sie mit der ärztlichen Kommunikation waren.

Methodik: 101 Patienten mit neu diagnostiziertem Lungenkrebs wurden kurz nach der Aufklärung über die Diagnose, die Therapie und das Therapieziel zu dem ärztlichen Gespräch befragt. Die aufklärenden Ärzte wurden gebeten, den Inhalt des Aufklärungsgesprächs anzugeben. Die Antworten der Patienten und Ärzte wurden verglichen.

Ergebnisse: 86\% (86 von 100 Patienten) kannten ihre Diagnose, 81 \% erinnerten den Therapievorschlag richtig und $42 \%$ wussten, ob das Therapieziel kurativ oder palliativ war. Wir fanden eine hohe Zufriedenheit über die Kommunikation der Diagnose und der Therapie (83\% resp. 77\%). Die Zufriedenheit mit dem Gespräch über das Therapieziel war mit 53\% (51 von 97 Patienten) signifikant niedriger als die Zufriedenheit über die Kommunikation der Diagnose und der Therapie. Patienten, die von männlichen Ärzten aufgeklärt wurden, waren signifikant zufriedener mit dem Gespräch hinsichtlich des Therapieziels.

Schlussfolgerungen: Behandlungsziele sind schwer von Ärzten zu vermitteln, die in der Gesprächsführung nicht geschult sind. Weitere Untersuchungen sind notwendig, um zu verstehen, wie wir das Verständnis und die Zufriedenheit der Patienten mit der Kommunikation über das Therapieziel verbessern können. 


\section{Introduction}

\section{$\nabla$}

In the past years communication skills of physicians disclosing cancer, the effect of skills trainings on physicians' communication, and on the needs of patients being confronted with diagnosis of cancer have been investigated extensively [1 -3]. Patients wish that physicians disclose reliably and name prognosis honestly $[2,4,5]$. Patient-centred communication includes shared decision-making regarding therapy and may lead to better acceptance and adherence of patients in the course of treatment [6]. During a disclosure it is necessary that physicians ensure that patients understand all important information [7]. Patients tend to underestimate the extent of the disease and overestimate their chance of cure $[2,4,8]$. This may lead to misunderstanding and lack of recollection about the goal of treatment (palliative versus curative).

The design of this study is based on a previous study performed at a department of Pneumology in Basel, Switzerland, with 71 lung cancer patients [9]. The Basel study showed that patients did not know if the aim of therapy was curative or palliative, although they had understood they have lung cancer and knew the therapy proposed to them. $61 \%$ of the patients were not satisfied with communication about the individual treatment goals.

The aim of the Berlin study was to replicate the Basel study on a wider scale to improve validity, to promote a progressive mindset and to consider the following questions:

Why is it that patients don't understand and/or are not sufficiently satisfied with the communication(s) from the physician?

How do we make these conversations easier for both?

\section{Methods and patient selection}

\section{$\nabla$}

All consecutive patients with new diagnosed lung cancer between February 2010 and October 2010 were eligible for the study. The stage of Lung cancer was in accordance with the seventh edition of the TNM Classification of Malignant Tumours [10]. All treatments of lung cancers in stadium I, II, IIIa and IIIB had a curative intention - knowing that stage IIIb has a poor outcome. All stage IV lung cancers were regarded to be in a palliative situation. Those patients fulfilling the inclusion criteria (fluency in German and not critically ill) were approached 1 to 3 days after the diagnosis of lung cancer had been disclosed. The Ethical Committee of Berlin Medical University (Charité) approved the study and written informed consent was obtained from each patient. A total of 117 patients met the eligibility criteria. 12/117 (10\%) declined participation, and 4/117 (3\%) were lost to follow-up. Records were excluded from analyses when incomplete. If the patient was unavailable to meet in person, the questionnaire was administered by telephone. Complete data sets were available for $101 / 117$ (86\%) of patients.

All 28 physicians who did the disclosure conversations were approached and agreed to participate (28/28, 100\%). Four were pulmonary specialists, and 24 were residents.

\section{Measures}

Patient information recall and satisfaction with communication were elicited with a structured interview. Two interviewers were blinded to the content of prior physician-patient communication. After disclosure of diagnosis physicians completed a report of information regarding diagnosis, treatment procedure, and goal of treatment within 72 hours.
In accordance with the previous study [9] patients were asked the following three questions:

1. "What did your physician tell you about your diagnosis?"

2. "What did your physician tell you about the treatment procedure?"

3. "Did the physician discuss the treatment goal?"

Responses regarding diagnosis were rated "fully congruent" when patients could say they had lung cancer with or without metastasis, "partially congruent" when they answered with only partial descriptions, and "incongruent" when they did not mention cancer. Answers about the treatment procedure were scored "fully congruent" when patients exactly described the treatment procedure, "partially congruent" when they had mentioned part of the proposed treatment procedure, and "incongruent" when they answered otherwise.

With respect to treatment goal patients' answers were only rated "fully congruent" if they could recall whether the primary goal was to cure or palliate the cancer.

Satisfaction with communication was assessed by the following questions:

1. "How would you rate the way the diagnosis of cancer was discussed with you?"

2. "How would you rate the way the treatment procedure for your cancer was discussed with you?"

3. "How would you rate the way the goal of treatment was discussed with you?"

Patients could choose five different levels: excellent, good, satisfactory, inadequate or poor.

Patients were administered the German version of the validated European Organization for Research and Treatment of Cancer Quality of Life Questionnaire QLQ-C30 (EORTC QLQ-C30) [11], and the Hospital Anxiety and Depression Scale (HADS) [12] regarding quality of life, depression and anxiety.

\section{Statistical Analyses}

Regarding satisfaction measures, response options were prioritized into two groups: HIGH (excellent/good) and MID-LOW SATISFACTION (satisfactory/inadequate/poor). Sociodemographic data and ratings of physician's communication were characterized by descriptive statistics. Quantitative variables were summarized as means \pm standard deviations (SD). For comparisons of categorical variables between groups chi-square tests were used. Multivariate logistic regressions with forward selection (stepwise forward, $\mathrm{p}_{\text {in }} 0.05, \mathrm{p}_{\text {out }}=0.10$ ) were used to examine the extent to which patient characteristics and physician characteristics could predict patients' recall and satisfaction. The significance level for all tests was set to 0.05 .

\section{Results \\ $\nabla$}

Patient characteristics are summarized in Tab.1. The higher proportion of the sample was male (59\%), married (59\%), with children (76\%), retired (74\%). $41 \%$ of patients were accompanied during the disclosure of diagnosis.

"Quality of life" measure is shown in $\bullet$ Fig. 1. The sample of this study had a high score for the functional scales, a high or healthy level of functioning, and a low level of physical symptoms. In the fatigue and dyspnea scale, patients scored slightly higher than in the other symptom scales. The score for the global health status is high. 
Table 1 Patients' sociodemographic and disease-related characteristics.

\begin{tabular}{|llcr|}
\hline Characteristics & & Patients \\
& & No. & $\%$ \\
\hline Total no. of patients & & 101 & \\
\hline Age & mean ( \pm SD) & $66.5( \pm 10)$ & \\
\hline Sex, male & & 60 & 59 \\
\hline Civil state & never married & 9 & 9 \\
\hline & married & 60 & 59 \\
\hline & widower & 11 & 11 \\
\hline & divorced & 17 & 17 \\
\hline & seperated & 1 & 1 \\
\hline Children & in relationship & 3 & 3 \\
\hline & none & 24 & 24 \\
\hline & 1 & 24 & 24 \\
\hline & 2 & 36 & 36 \\
\hline Country of birth & 3 & 5 & 5 \\
\hline & 4 and more & 12 & 12 \\
\hline & Germany & 84 & 83 \\
\hline Education & EU & 10 & 10 \\
\hline Employment & non-EU & 7 & 7 \\
\hline Stage of disease & academic & 12 & 13 \\
\hline & employed & 26 & 26 \\
\hline & I & 2 & 2 \\
\hline Treatment approach & II & 10 & 10 \\
\hline & III & 27 & 27 \\
\hline & curative approach & 28 & 28 \\
\hline & palliative approach & 73 & 72 \\
\hline
\end{tabular}

The prevalence of HADS scores indicative of anxiety disorder and depression were $8 \%$ and $11 \%$, respectively.

Patient recall of diagnosis, treatment procedure, and goal of treatment is presented in Tab.2. Patient recall of information was high: regarding diagnosis it was fully congruent in 86 of 100 (86\%) patient cases; in 78 of 96 (81\%) patient cases it was fully congruent with the information about treatment procedure; and in 39 of 93 (42\%) cases it was fully congruent re- garding treatment goal. Recall of goal of treatment was significantly worse than recall of diagnosis or of treatment procedure $(p<0.001)$.

Of the 26 patients who were informed that the therapeutic approach was to be curative, six of them (23\%) recalled this information fully, compared with 33 of 67 (49\%) patients in the palliative care group.Congruence of this information was significant higher among patients in the palliative care group $(p=0.021)$. Patients were highly satisfied with communication of diagnosis (83/100; 83\%); likewise with treatment procedure (75/97; 77\%) ( Tab.3). However, satisfaction with communication of the treatment goal was 53\% (51/97) and significantly lower than satisfaction with communication of diagnosis $(\mathrm{p}<0.001)$ and satisfaction with communication of treatment procedure $(p<0.001)$. There was no significant difference between patients with curative $(11 / 27 ; 41 \%)$ versus palliative goal $(40 / 70 ; 57 \%)$ regarding satisfaction with communication of treatment goal $(p=0.147)$.

Patients who were informed by male physicians were significantly more satisfied with the disclosure about the treatment goal $(p=0.007)$ ( Tab.5). Further, patients who were disclosed by male physicians recalled the treatment goal significantly better $(p=0.027)$, and patients with progressed disease (stage IIIB and IV) did understand the treatment goal significantly better than patients with limited disease $(p=0.018)(\bullet$ Tab.4).

Sociodemographic and disease-related characteristics of the Berlin sample are similar to those of the Basel sample. In the Berlin study more patients were treated with palliative approach (72\%) than in the Basel study (52\%). Scores of the EORTC QLQ-C30 questionnaires in this study comply with the results of the Basel study.

Recall of diagnosis was significant better in the Berlin study (86\%) than in the Basel study ( $57 \%)(\mathrm{p}<0.001)$. Recall of treatment procedures and the treatment goal was similar in both studies.

In both studies satisfaction with communication of diagnosis and treatment procedure was comparable (76\% versus $83 \%$ and $73 \%$ versus $77 \%$ ). Satisfaction with communication of the treatment goal was slightly better in the Berlin study (53\% versus 39\%).

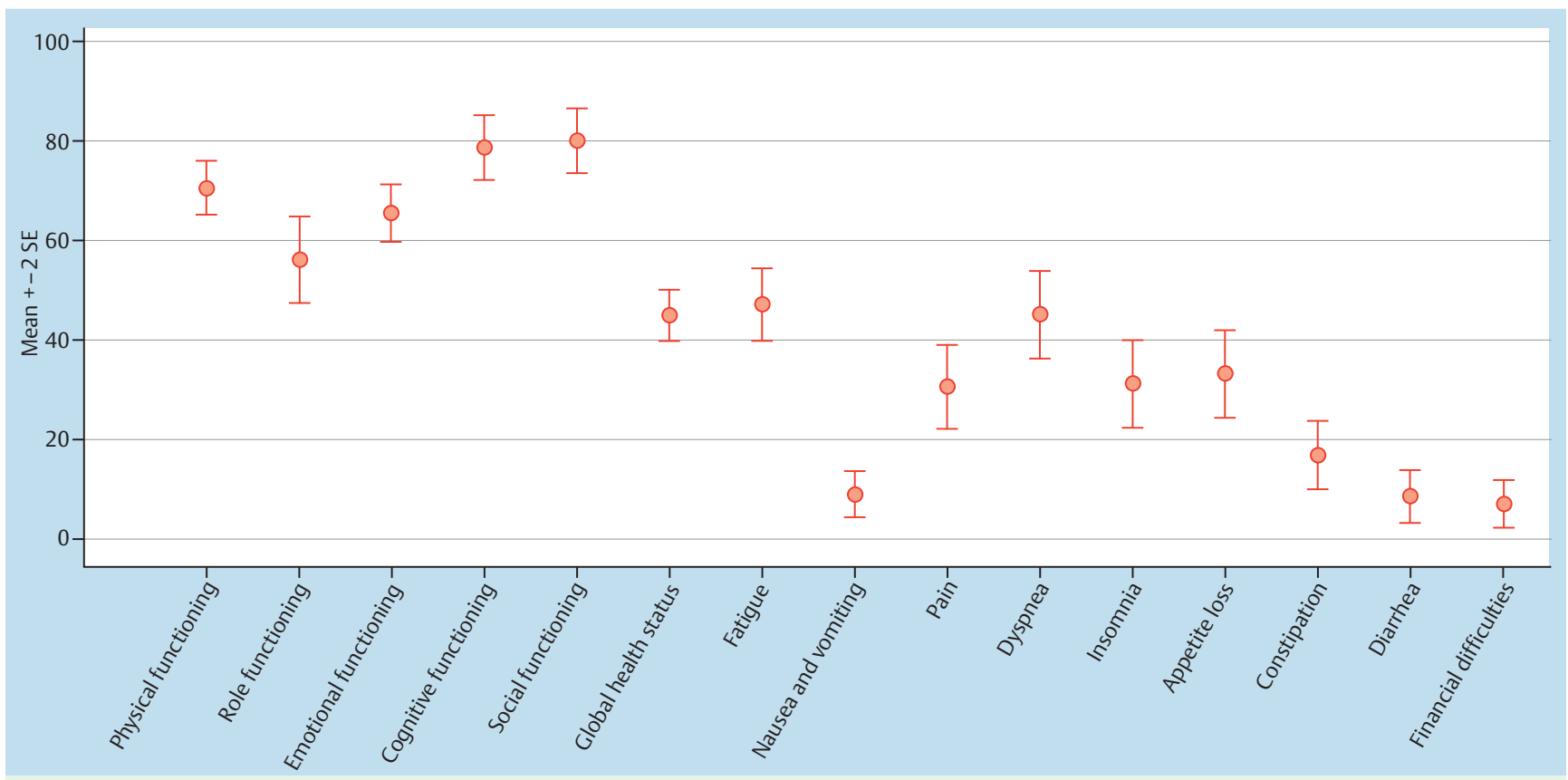

Fig. 1 Mean scores for the European Organisation for Research and Treatment of Cancer Quality of Life Questionnaire (EORTC) QLQ-C30 for patients. 
Table 2 Congruence between physicians' information and patients' recall regarding diagnosis, the treatment procedure, and the goal of treatment.

\begin{tabular}{|c|c|c|c|c|c|c|c|}
\hline \multirow[t]{3}{*}{ Physician's information } & \multicolumn{7}{|c|}{ Congruence of patient and physician } \\
\hline & \multirow[b]{2}{*}{$N_{\text {total }}{ }^{1}$} & \multicolumn{2}{|c|}{ Fully congruent } & \multicolumn{2}{|c|}{ Partially congruent } & \multicolumn{2}{|c|}{ Incongruent } \\
\hline & & No. & $\%$ & No. & $\%$ & No. & $\%$ \\
\hline Diagnosis & 100 & 86 & 86 & 10 & 10 & 4 & 4 \\
\hline Treatment procedure & 96 & 78 & 81,3 & 3 & 3,1 & 15 & 15,6 \\
\hline Treatment goal & 93 & 39 & 42 & - & - & 54 & 58 \\
\hline Curative & 26 & 6 & 23 & - & - & 20 & 77 \\
\hline Palliative & 67 & 33 & 49 & - & - & 34 & 52 \\
\hline
\end{tabular}

${ }^{1}$ Due to missing data, $\mathrm{N}_{\text {total }}$ differs from 101. Percentages were calculated using indicated totals.

\begin{tabular}{|llllll|}
\hline \multicolumn{2}{|c|}{ Patient satisfaction with communication } \\
& \multicolumn{3}{c|}{ High } & \multicolumn{3}{l|}{ Mid to low } \\
\hline & No. & No. & $\%$ & No. & $\%$ \\
\hline Diagnosis & 100 & 83 & 83 & 17 & 17 \\
\hline Therapy & 97 & 75 & 77 & 22 & 23 \\
\hline Treatment goal & 97 & 51 & 53 & 46 & 47 \\
\hline Curative & 27 & 11 & 41 & 16 & 59 \\
\hline Palliative & 70 & 40 & 57 & 30 & 43 \\
\hline
\end{tabular}

Table 3 Patients' satisfaction with communication about diagnosis, treatment procedures, and goal of treatment.

\begin{tabular}{|c|c|c|c|}
\hline & \multicolumn{3}{|c|}{ Patients' recall of treatment goal and prognosis } \\
\hline & Correct recall & Incorrect recall & p-value \\
\hline \multicolumn{4}{|l|}{ Physician factor, n (\%) } \\
\hline Age ( $>34.5$ years), in 46 of 93 cases ( $49.5 \%$ ) & $24 / 39(61.5 \%)$ & $22 / 54(41 \%)$ & $p=0,048$ \\
\hline Sex (male), 53/93 (57\%) & $29 / 39(74 \%)$ & $24 / 54(44 \%)$ & $p=0,004$ \\
\hline \multicolumn{4}{|l|}{ Patient factor, n (\%) } \\
\hline Sex (male), 54/93 (58\%) & $22 / 39(56 \%)$ & $32 / 54(60 \%)$ & $p=0,784$ \\
\hline Married, 55/93 (59\%) & $23 / 39(59 \%)$ & $32 / 54(59 \%)$ & $p=0,978$ \\
\hline Children (yes), 71/93 (76\%) & $30 / 39(77 \%)$ & $41 / 54(76 \%)$ & $p=0,911$ \\
\hline German, 76/93 (82\%) & $29 / 39(74 \%)$ & $47 / 54(87 \%)$ & $p=0.119$ \\
\hline Employed, 22/93 (24\%) & $8 / 39(20,5 \%)$ & $14 / 54(26 \%)$ & $p=0.554$ \\
\hline Academic (yes), 12/93 (13\%) & $7 / 12(58 \%)$ & $5 / 12(42 \%)$ & $p=0.217$ \\
\hline Stage (IIIb, IV), 74/93 (80\%) & $37 / 39(95 \%)$ & $37 / 54(68,5 \%)$ & $p=0,002$ \\
\hline Accompanied, 38/93 (41\%) & $20 / 39(51 \%)$ & $18 / 54(33 \%)$ & $p=0.082$ \\
\hline GHS (>50), 34/93 (37\%) & $12 / 39(31 \%)$ & $22 / 54(41 \%)$ & $p=0,324$ \\
\hline Depressive, 10/91 (11\%) & $3 / 38(8 \%)$ & $7 / 53(13 \%)$ & $p=0,424$ \\
\hline DMP congruent, 40/93 (43\%) & $15 / 39(38,5 \%)$ & $25 / 54(46 \%)$ & $p=0,451$ \\
\hline Religion (yes), 52/93 (56\%) & $24 / 39(61,5 \%)$ & $28 / 54(52 \%)$ & $p=0,353$ \\
\hline Living alone, 27/93 (29\%) & $11 / 39(28 \%)$ & $16 / 54(30 \%)$ & $p=0,881$ \\
\hline
\end{tabular}

Table 4 Univariate analyses of patients' and physicians' factors associated with patients' recall of the treatment goal and prognosis.

\section{Discussion}

For the most part the results of the Basel study could be confirmed in the Berlin study. Deviant from the results of the Basel study, patients in Berlin recalled significantly better which diagnosis had been disclosed. Comparable to the Basel results recall of treatment procedure were good, recall of the treatment goal and prognosis lower. Similar to the Basel study patients in Berlin were satisfied with communication about diagnosis and treatment procedure, less satisfied with communication about the treatment goal and prognosis.

Academic status of patients had no influence on the results. It was not significant and not even a non-significant trend (10-20\%; $\mathrm{p}=0.217$ ) that academics recall the goal of therapy better and were more satisfied with the conversation about the goal of therapy. We therefore think that this issue cannot be supported by our data. However, we found a non-significant trend that, patients who had been accompanied by a relative or loved one for the disclosure of diagnosis had a better recall of the goal of treatment ( $p=0.082$ ). In contrast to academic status we think that this factor may be important and only hampered by the sample size of the study. Future studies need to further evaluate this factor. Salient is that only a small number of patients presented with depression or anxiety ( $8 \%$ and $11 \%$, respectively), similar to the Basel study ( $7 \%$ and $12.7 \%$ ). In the general population and within cancer patients other authors mention twenty to twenty-five percent for depression and anxiety [13-16]. Depression has no influence on recall of information and satisfaction with communication after the disclosure of diagnosis.

Patients' recall of diagnosis and treatment procedure after disclosure of lung cancer diagnosis was very good, whereas recall regarding treatment goal and prognosis was worse. Similar results revealed a study by Weeks et al [17]. Other authors discovered that patients are overwhelmed by medical details during the disclosure of diagnosis $[18,19]$. Further explanations for insufficient patient knowledge after disclosure of lung cancer might be found 
Table 5 Univariate analyses of patients' and physicians' factors associated with patients' satisfaction with communication of the treatment goal and prognosis.

\begin{tabular}{|c|c|c|c|}
\hline & \multicolumn{3}{|c|}{ Patients' satisfaction with communication of the treatment goal and prognosis } \\
\hline & Satisfied & Not satisfied & p-value \\
\hline \multicolumn{4}{|l|}{ Physician factor, $\mathbf{n}(\%)$} \\
\hline Age (>34.5 years), in 46 of 97 cases ( $47 \%)$ & $27 / 51(53 \%)$ & $19 / 46(41 \%)$ & $p=0,252$ \\
\hline Sex (male), 54/97 (56\%) & $35 / 51(69 \%)$ & $19 / 46(41 \%)$ & $p=0,007$ \\
\hline \multicolumn{4}{|l|}{ Patient factor, n (\%) } \\
\hline Sex (male), 58/97 (60\%) & $33 / 51(65 \%)$ & $25 / 46(54 \%)$ & $p=0,299$ \\
\hline Married, 57/97 (59\%) & $30 / 51(59 \%)$ & $27 / 46(59 \%)$ & $p=0,990$ \\
\hline Children (yes), 74/97 (76\%) & $37 / 51(72,5 \%)$ & $37 / 46(80 \%)$ & $p=0,362$ \\
\hline German, $80 / 97(82,5 \%)$ & $43 / 51(84 \%)$ & $37 / 46(80 \%)$ & $p=0,616$ \\
\hline Employed, 25/97 (26\%) & $16 / 51(31 \%)$ & $9 / 46(20 \%)$ & $p=0,184$ \\
\hline Academic (yes), 12/97 (12\%) & $7 / 12(58 \%)$ & $5 / 12(42 \%)$ & $p=0.670$ \\
\hline Stage (IIIb, IV), 75/97 (77\%) & $41 / 51(80 \%)$ & $34 / 46(74 \%)$ & $p=0,447$ \\
\hline Accompanied, 41/97 (42\%) & $22 / 51(43 \%)$ & $19 / 46(41 \%)$ & $p=0,855$ \\
\hline GHS (>50), 36/96 (37,5\%) & $21 / 51(41 \%)$ & $15 / 45(33 \%)$ & $p=0,428$ \\
\hline Depressive, $11 / 95$ (12\%) & $3 / 49(6 \%)$ & $8 / 46(17 \%)$ & $p=0,086$ \\
\hline DMP congruent, $43 / 97$ (44\%) & $21 / 51(41 \%)$ & $22 / 46(48 \%)$ & $p=0,510$ \\
\hline Religion (Yes), 56/97 (58\%) & $25 / 51(49 \%)$ & $31 / 46(67 \%)$ & $p=0,067$ \\
\hline Living alone, 29/97 (30\%) & $14 / 51(27,5 \%)$ & $15 / 46(33 \%)$ & $p=0,580$ \\
\hline
\end{tabular}

with physicians. Unlike other countries, training of communication skills has not been established on a university level [2022]. With adequate training physicians' communication skills can be improved [23-25].

It is remarkable that more patients recall the palliative treatment goal. Perhaps the "bad news" is not as difficult for the patient to absorb as the physician might think it is.

Other studies have shown that patients often underestimate the extent of their disease and overestimate prognosis $[8,26]$. In the present study patients more often failed to hear the chance of cure with appropriate therapy. This suggests they have underestimated their prognosis. This may be because the patient associates cancer with death, and does not hear the possibility of a curative approach.

Usually physicians disclose the diagnosis first. Treatment options, treatment goal and prognosis are mentioned in the second half of the disclosure conversation. Under time pressure these rather sensitive fields for patients, and burdening themes for physicians, may get less attention [27]. Especially in case of bad prognosis physicians without previous training in communication tend to withdraw part of the information to protect the patient $[28,29]$, and underestimate patients` need to be fully informed about their prognosis [30]. Maybe patients are less satisfied because they get insufficient information, insufficient time and empathy to process these facts.

Significantly more patients were satisfied with communication about treatment goal and prognosis if disclosed by a male physician. In previous studies satisfaction was dependent on the physician's competence to show empathy $[6,31]$, female physicians were ranked better for their communication skills than male physicians [32]. In this recent study male physicians may have discovered a new way of empathic communication.

More patients in the Berlin study recalled the palliative treatment goal than in the Basel study. The Berlin study took place in a large certified lung cancer center with focus on consistent guidelines regarding diagnosis and treatment procedures and with established palliative care. Furthermore this center provides patients with valuable written information about the course of lung cancer. This fact might influence the disclosing conversation and influences the recollection of the palliative treatment goal significantly.

\section{Limitations}

To avoid influence on the way physicians communicate physician-patient interaction was not documented at the time. Neither videotapes nor audiotapes nor the length of interaction were recorded. Without documentation it is impossible to tell what really happened and what information the physician provided, or how sensitive, empathetic, clearly worded, thorough, or honest the physicians' approach was, or the patient's reaction of course, which is critical indeed.

In summary, a representative sample of newly diagnosed lung cancer patients was investigated in a specialized lung cancer center. Patients' recall of and satisfaction with information about diagnosis and treatment procedure was very good and moderately good about the treatment goal and prognosis. More patients recalled the palliative treatment goal and patients were significantly more satisfied with communication about treatment goal and prognosis if disclosed by a male physician. Further research is needed to understand how we can improve patients' recall of and satisfaction with information about the treatment goal and prognosis.

\section{Acknowledgement \\ $\nabla$}

We thank all the patient and physician participants for giving their time and energy to this study. We would like to thank Paul Black for reading and correcting our English. This paper is part of the doctorial thesis of W. Nehls. This study was supported by an unrestricted grant by the Oskar-Helene-Heim foundation, Berlin, Germany. 


\section{Conflict of Interest}

$\nabla$

The authors have no conflict of interest.

\section{Institutions}

${ }^{1}$ Klinik für Pneumologie, Lungenklinik Heckeshorn, HELIOS Klinikum

Emil von Behring, Berlin, Germany

2 Division of Psychosomatic Medicine, University Hospital, Basel, Switzerland

${ }^{3}$ Abteilung für Onkologie und Palliativmedizin der Medizinischen Klinik 1,

HELIOS Klinikum Wuppertal, Germany

${ }^{4}$ Klinik für Psychosomatische Medizin und Psychotherapie, HELIOS Klinikum Emil von Behring, Berlin, Germany

${ }^{5}$ Berufsgenossenschaftliches Universitätsklinikum Bergmannsheil GmbH, Medizinische Klinik III - Klinik für Pneumologie, Allergologie, Schlaf- und Beatmungsmedizin, Bochum, Germany

\section{References}

1 Fallowfield L. Giving sad and bad news. Lancet 1993; 341: 476-478

2 Schofield PE, Butow PN, Thompson JF et al. Psychological responses of patients receiving a diagnosis of cancer. Ann Oncol 2003; 14: 48 - 56

3 Butow PN, Maclean M, Dunn SM et al. The dynamics of change: cancer patients' preferences for information, involvement and support. Ann Oncol 1997; 8: 857-863

4 Fallowfield L, Jenkins V, Farewell V et al. Efficacy of a Cancer Research UK communication skills training model for oncologists: a randomised controlled trial. Lancet 2002; 359: 650-656

5 Schapira L, Butow P, Brown R et al. Pessimism is no poison. J Clin Oncol 2010; $28: 705-707$

6 Stewart $M$. What is a successful doctor patient interview? a study of interactions and outcomes Soc Sci Med 1984; 19: 167-175

7 Lobb E, Butow P, Kenny D. Communicating prognosis in early breast cancer: do women understand the language used? Med J Aust 1999; 171: $290-294$

8 Quirt C, Mackillop W, Ginsburg A et al. Do doctors know when their patients don't? A survey of doctor-patient communication in lung cancer Lung Cancer 1997; 18: 1 - 20

9 Gabrijel S, Grize L, Helfenstein E et al. Receiving the Diagnosis of Lung Cancer: Patient Recall of Information and Satisfaction With Physician Communication. J Clin Oncol 2008; 26 : 297-302

10 Sobin LH, Gospodarowicz MK, Wittekind C (eds.) International Union Against Cancer: TNM Classification of Malignant Tumours (ed. 7). West Sussex, United Kingdom: Wiley-Blackwell; 2009

11 Aaronson NK, Ahmedzai S, Bergman B et al. The European Organization for Research and Treatment of Cancer QLQ-C30: a quality-of-life instrument for use in international clinical trials in oncology. J Natl Cancer Inst 1993; 85: $365-376$

12 Zigmond AS, Snaith RP. The hospital anxiety and depression scale. Acta Psychiatr Scand 1983; 67: 361 - 370

13 Keller M, Sommerfeldt S, Fischer C et al. Recognition of distress and psychiatric morbidity in cancer patients: a multi-method approach. Ann Oncol 2004; 15: $1243-1249$
14 Taylor C, Graham J, Potts $H$ et al. Changes in mental health of UK hospital consultants since the mid-1990s. Lancet 2005; 366 : $742-744$

15 Parle $M$, Jones B, Maguire $P$. Maladaptive coping and affective disorders among cancer patients. Psychol Med 1996; 26 : 735-744

16 Bottomley A. Depression in cancer patients: a literature review. Eur J Cancer Care (Engl) 1998; 7: 181 -191

17 Weeks JC, Catalano PJ, Cronin A et al. Patients' expectations about effects of chemotherapy for advanced cancer. N Engl J Med 2012; 367: $1616-1625$

18 McCluskey L, Casarett D, Siderowf A. Breaking the news: a survey of ALS patients and their caregivers. Amyotroph Lateral Scler Other Motor Neuron Disord 2004; 5: 131 - 135

19 Yardley SJ, Davis CL, Sheldon F. Receiving a diagnosis of lung cancer: patients' interpretations, perceptions and perspectives. Palliat Med 2001; 15: 379 - 386

20 Schildmann J, Brunklaus A, Herrmann E et al. Evaluation of a 'breaking bad news' course at the Charité, Berlin. Med Educ 2001; 35: 806-807

21 van Dalen J, Kerkhofs E, van Knippenberg-Van Den Berg BW et al. Longitudinal and concentrated communication skills programmes: two dutch medical schools compared. Adv Health Sci Educ Theory Pract 2002; 7: 29-40

22 Barrows HS. An overview of the uses of standardized patients for teaching and evaluating clinical skills. AAMC. Acad Med 1993; 68: $443-451$; discussion 451-443

23 Baile WF, Lenzi R, Kudelka AP et al. Improving physician-patient communication in cancer care: outcome of a workshop for oncologists. J Cancer Educ 1997; 12: 166-173

24 Baile WF, Aaron J. Patient-physician communication in oncology: past present, and future. Curr Opin Oncol 2005; 17: 331 - 335

25 Barth J, Lannen P. Efficacy of communication skills training courses in oncology: a systematic review and meta-analysis. Ann Oncol 2011; 22: $1030-1040$

26 Weeks J, Cook E, O'Day S et al. Relationship between cancer patients predictions of prognosis and their treatment preferences. JAMA 1998 279: $1709-1714$

27 Thorne SE, Hislop TG, Stajduhar K et al. Time-related communication skills from the cancer patient perspective. Psychooncology 2009; 18 : $500-507$

28 Hagerty RG, Butow PN, Ellis PM et al. Communicating prognosis in cancer care: a systematic review of the literature. Ann Oncol 2005; 16: $1005-1053$

$29 \operatorname{Rogg} L$, Loge JH, Aasland OG et al. Physicians' attitudes towards disclosure of prognostic information: a survey among a representative cross-section of 1605 Norwegian physicians. Patient Educ Couns 2009; 77: $242-247$

30 Fumis R, De Camargo B, Del Giglio A. Physician, patient and family attitudes regarding information on prognosis: a Brazilian survey. Ann Oncol 2012; 23: 205-211

31 Epstein R, Hadee T, Carroll J et al. "Could this be something serious?" reassurance, uncertainty, and empathy in response to patients' expressions of worry J Gen Intern Med 2007; 22: 1731 - 1739

32 Hall JA, Blanch-Hartigan D, Roter DL. Patients' satisfaction with male versus female physicians: a meta-analysis. Med Care 2011; 49: 611 617 